\title{
A Highly Stable Gadolinium Complex Mechanism of Fast, Associative Water Exchange
}

\section{Supplemental Data}

\section{Synthesis}

[Gd-TREN-bisHOPO-(TAM-TRI) $\left(\mathbf{H}_{2} \mathbf{O}\right)_{2}$ ] (Gd-2): The total synthesis of TREN-bisHOPO-(TAMTRI) (2) will be published completely elsewhere. TREN-bisHOPO-(TAM-TRI).HCl.3.5 $\mathrm{H}_{2} \mathrm{O}(0.1040 \mathrm{~g}$, $0.117 \mathrm{mmol})$ and $\mathrm{Gd}(\mathrm{acac})_{3} .2 \mathrm{H}_{2} \mathrm{O}(0.0574 \mathrm{~g}, 0.121 \mathrm{mmol})$ were combined in $\mathrm{MeOH}(20 \mathrm{ml})$ and stirred at room temperature until dissolution occurred. The solution was refluxed for $1 \mathrm{~h}$ then pyridine $(0.131 \mathrm{~g}, 1.66$ $\mathrm{mmol})$ in $\mathrm{MeOH}(2 \mathrm{ml})$ was added and reflux continued for $5 \mathrm{~h}$. Evaporation of the solvent yielded a yellow powder which was purified by column chromatography (Sephadex LH-20, eluent: MeOH). The crystalline product isolated was dissolved in $\mathrm{MeOH}(2 \mathrm{ml})$ and added to a rapidly stirring solution of diethyl ether $(450 \mathrm{ml})$. This mixture was stirred overnight, filtered and the yellow residue dried in vacuum overnight (yield: 0.107 g, 92 \%). Anal. Calc. for H[Gd-2]. $5 \mathrm{H}_{2} \mathrm{O}$ (Found): C, 40.48 (40.41); H, 5.66 (5.36); $\mathrm{N}, 9.18$ (8.93). ES-MS (-), $\mathrm{m} / \mathrm{z} 941[\mathrm{M}]^{-}$. The isotopic abundance of the cluster centered at $\mathrm{m} / \mathrm{z}=941$ is characteristic of a mononuclear Gd-containing specie and matches the simulated isotopic distribution.

[Y-TREN-bisHOPO-(TAM-TRI) $\left(\mathrm{H}_{2} \mathrm{O}\right)_{2}$ ] (Y-2): The above synthetic methodolgy was used with the exception that $\mathrm{YCl}_{3} \cdot 6 \mathrm{H}_{2} \mathrm{O}$ was used as the lanthanide salt. Quantities of reagents: $\mathrm{YCl}_{3} \cdot 6 \mathrm{H}_{2} \mathrm{O}(18.0 \mathrm{mg}$, $\left.5.93 \times 10^{-5} \mathrm{~mol}\right)$, TREN-bisHOPO-(TAM-TRI). $\mathrm{HCl} .4 \mathrm{H}_{2} \mathrm{O}\left(48.2 \mathrm{mg}, 5.38 \times 10^{-5} \mathrm{~mol}\right)$, pyridine (33.0 mg, $4.18 \times 10^{-4} \mathrm{~mol}$ ), $\mathrm{MeOH}(22 \mathrm{ml})$. A pale-brown solid was isolated (yield: $50.0 \mathrm{mg}, 86 \%$ ). Anal. Calc. for $\mathrm{H}[\mathrm{Y}-2] . \mathrm{H}_{2} \mathrm{O} .1 .5 \mathrm{CH}_{3} \mathrm{OH} .3 \mathrm{HCl}$ (Found): C, 41.51 (41.62); H, 5.67 (5.39); N, 9.03 (9.06). ES-MS (-), m/z $872.3[\mathrm{M}]^{-}$.

Ligand protonation constants. Potentiometric titration experiments were performed on ligand 2. A weighed portion of the ligand was dissolved in electrolyte solution (giving $\sim 4 \times 10^{-4} \mathrm{M}$ ) with an addition of acid to protonate the fifth basic site. The material was titrated from $\mathrm{pH} 4$ to $\mathrm{pH} 12$ with $\mathrm{KOH}$ and in reverse with $\mathrm{HCl}$. Three experiments were performed yielding six titrations in all. The pairwise sets of protonation titrations were combined for simultaneous refinement using the program HYPERQUAD. Both proton and ligand concentrations were refined with the shifts in ligand concentration for each pair of titrations being constrained to be equal.

Gd complexation constants. Equimolar solutions of the metal and respective ligand were titrated over the pH range 3-9 with spectral measurements being recorded. Collection of spectrophotometric measurements required a relatively dilute $(\sim 40 \mu \mathrm{M})$ concentration of the complex so an external source of $\mathrm{pH}$ buffering was added to the solutions (HEPES and MES buffers, $\sim 5 \times 10^{-4} \mathrm{M}$ ). Ligand and metal concentrations of $\sim 20$ $\mu \mathrm{M}$ were used. Each pair of titrations (i.e., forwards against $\mathrm{KOH}$ and reverse against $\mathrm{HCl}$ ) was combined for simultaneous refinement. Spectral data derived from the titrations with $\mathrm{Gd}^{3+}$ were analyzed using the program $\mathrm{pHAB}$. Typically a spectrum comprising absorbance measurements at wavelengths between 340 and $380 \mathrm{~nm}$ were included in the refinement for each point in the titrations. 
Figure S1. Representative data from spectrophotometric titration experiments. Experimental data (top) and calculated (bottom) spectra for a titration of 2 with $\mathrm{Gd}^{\mathrm{III}}$.
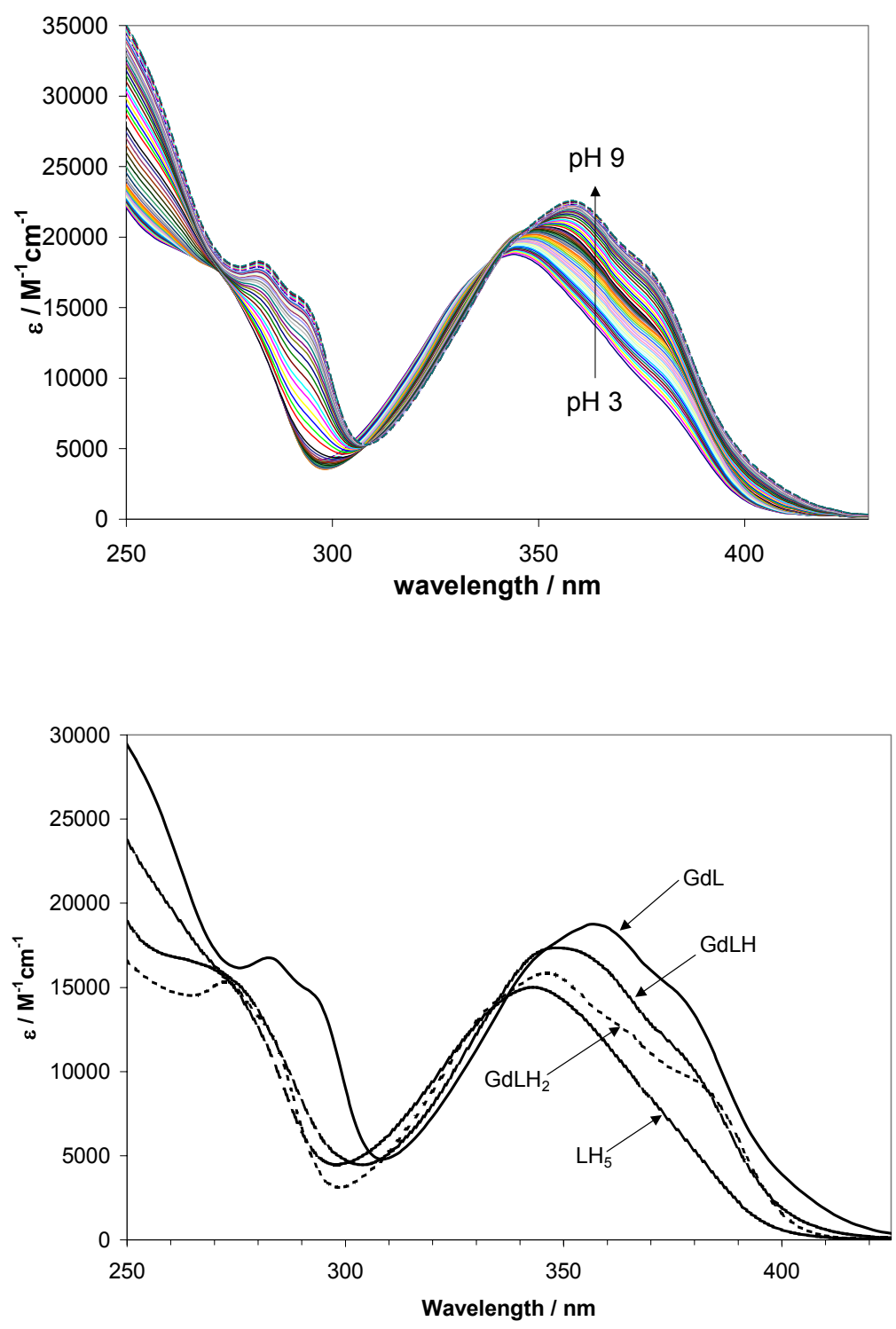
Table S1. Determined protonation and formation constants and calculated pM values for the $\mathrm{Gd} / \mathbf{2}$ system. Data for $\mathbf{1}$ are taken from references 5 and 11. All ligand protonation constants are the result of at least thee independent measurements. Figures in parentheses give the standard deviation in the least significant figure as determined by the variation between determinations. $\mathrm{pM}$ values give the free metal concentration calculated using the formation constants in the table and the conditions of $\mathrm{pH} 7.4,[\mathrm{Gd}]=1 \times 10^{-6}$ and $[\mathrm{L}]=$ $1 \times 10^{-5} \mathrm{M}\left(25^{\circ} \mathrm{C}, I=0.1 \mathrm{M}\right)$. Constants obtained were averaged from six independent experiments.

\begin{tabular}{|c|c|c|c|c|}
\hline \multirow{2}{*}{$\begin{array}{c}\text { Ligand } \\
\mathrm{mlh}\end{array}$} & \multicolumn{2}{|c|}{2} & \multicolumn{2}{|c|}{1} \\
\hline & $\log \beta_{\mathrm{mlh}}$ & $\log K_{m 1 h}$ & $\log \beta_{\mathrm{mlh}}$ & $\log K_{m 1 h}$ \\
\hline 011 & & $11.15(9)$ & & $11.42(7)$ \\
\hline 012 & & $8.63(2)$ & & $8.14(3)$ \\
\hline 013 & & $7.36(2)$ & & $7.05(1)$ \\
\hline 014 & & $6.11(3)$ & & $5.75(1)$ \\
\hline 015 & & $5.39(4)$ & & $4.98(6)$ \\
\hline 110 & $24.9(1)$ & & 24.1(1) & \\
\hline 111 & $30.6(2)$ & 5.7 & $29.7(2)$ & 5.6 \\
\hline 112 & $34.1(1)$ & 3.5 & $34.3(2)$ & 4.6 \\
\hline $\mathrm{pM}$ & & & & \\
\hline
\end{tabular}


Figure S2. Spectrophotometric competition titration of the $2 / \mathrm{Gd} / \mathrm{DTPA}$ system. [Gd] $=66.0 \mu \mathrm{M},[2]=66.0$ $\mu \mathrm{M},[\mathrm{DTPA}]=0-15.9 \mathrm{mM} . \mathrm{pH}=6.01(2), I=0.1 \mathrm{M} \mathrm{KCl}$.

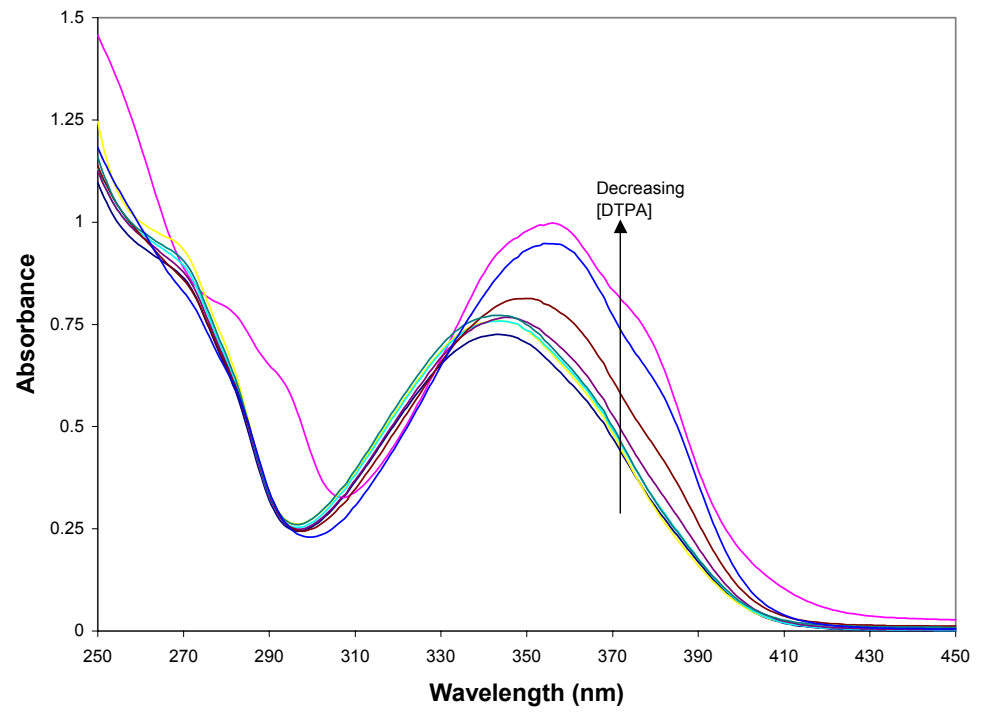


Figure S3. Plot of the data from the competition titration shown in Figure S2. The x-intercept (-0.31) indicates the difference in pGd between 2 and DTPA. [Gd] $=66.0 \mu \mathrm{M} ;[2]=66.0 \mu \mathrm{M}$; [DTPA] $=4.34 \times 10^{-}$ ${ }^{5} \mathrm{M}-3.63 \times 10^{-4} \mathrm{M} ; \mathrm{pH}=6.01(2) ; I=0.1 \mathrm{M} \mathrm{KCl}$.

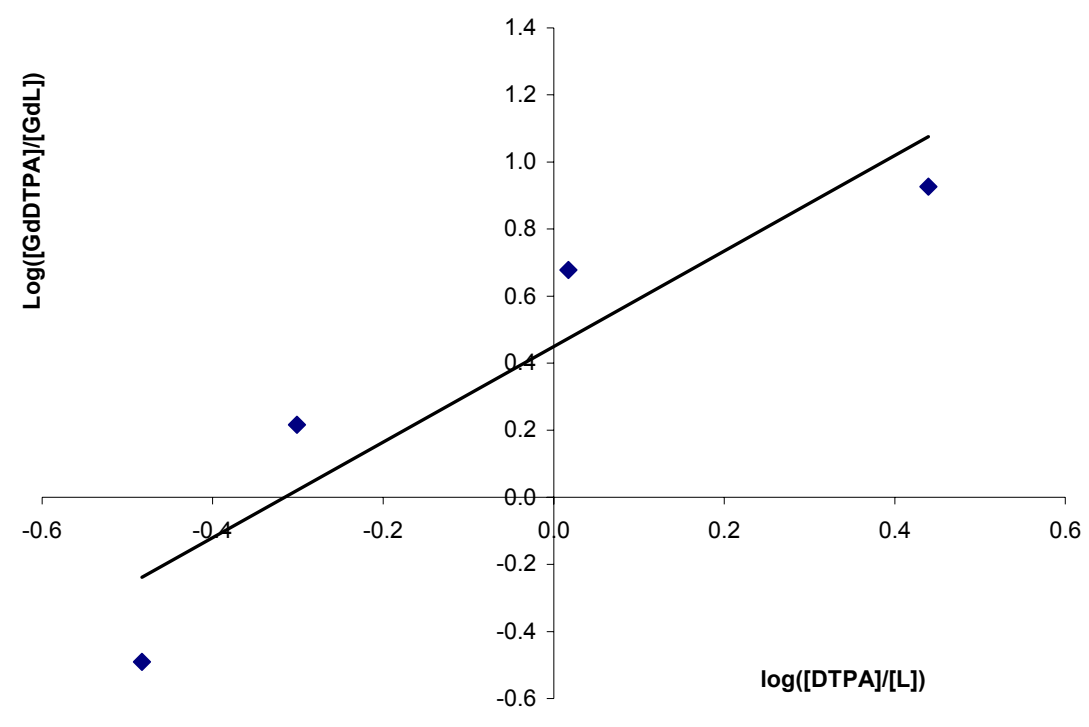

From this competition titration, the resulting pGd of 2 at pH 6.0 is 16.1 (pGd of DTPA $=16.4$ at $\mathrm{pH} 6.0$ ). This is in very close agreement to the calculated pGd of 16.3 (at $\mathrm{pH} 6.0$ ) using the formation constants in Table S1, thereby confirming the high affinity of $\mathbf{2}$ for $\mathrm{Gd}^{\mathrm{III}}$. 
Figure S4. Nuclear Magnetic Relaxation Dispersion (NMRD) profile of Gd-2.

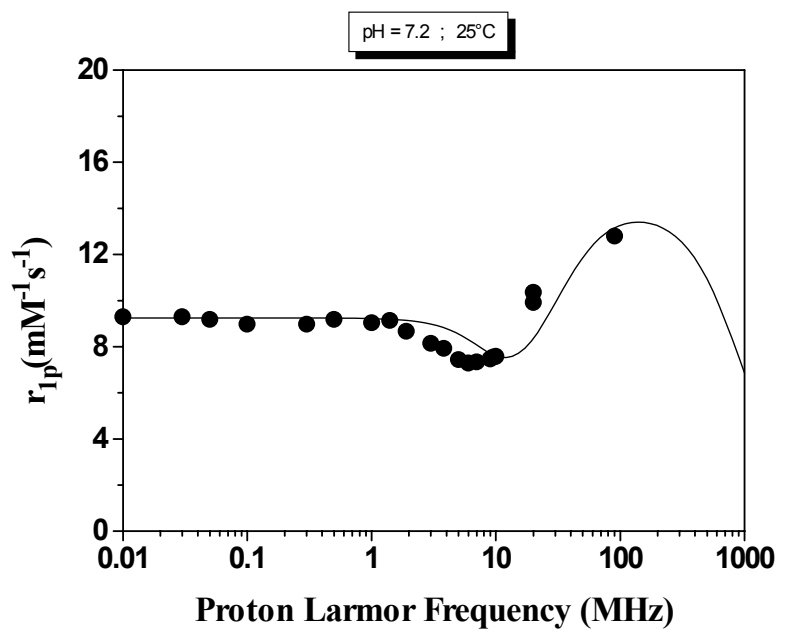




\section{Variable high pressure ${ }^{17} \mathrm{O}$ NMR}

\section{Experimental}

High pressure ${ }^{17} \mathrm{O}$ NMR measurements were performed up to $200 \mathrm{MPa}$ on a Bruker ARX 400 spectrometer $(9.4 \mathrm{~T}, 54.2 \mathrm{MHz})$ equipped with a homebuilt probe $\mathrm{e}^{[\mathrm{i}]}$. The temperature was set to $319.9 \mathrm{~K}$ by circulating a thermostated liquid through the probe and measured using a built-in Pt resistor. The solutions of the paramagnetic chelate $\left[\mathrm{Gd}(\mathrm{TREN}-\text { bisHOPO-TAM-TRI })\left(\mathrm{H}_{2} \mathrm{O}\right)_{2}\right]^{-}$and of the diamagnetic reference of the $\mathrm{Y}$ (III) analogue were enriched in ${ }^{17} \mathrm{O}$ to $2 \%$, using $10 \%{ }^{17} \mathrm{O}$-enriched water (Yeda R\&D Co., Rehovot, Israel). The $\mathrm{pH}$ was fixed to 8.2. The transverse relaxation times, $\mathrm{T}_{2}$, were measured by the CPMG spinecho technique. ${ }^{[i i]}$

$\underline{\text { Results and discussion }}$

The increase of the ${ }^{17} \mathrm{O}$ transverse relaxation rates due to the presence of paramagnetic $\mathrm{Gd}(\mathrm{III}), R_{2 p}$, is calculated at variable pressure by equation [1].

$$
R_{2 p}=\frac{1}{T_{2 o b s}}-\frac{1}{T_{2 r e f}}
$$

The relaxation rates of the diamagnetic reference are calculated from a linear fit of the logarithms of the

experimental $1 / T_{2 \text { ref }}$ for each pressure where $1 / T_{2 \text { obs }}$ has been measured (see Table). From variable temperature data it can be seen that the chemical shift term, $\Delta \omega_{M}$, is negligible compared to $1 / T_{2 m}$ and $k_{e x}$.

$$
\begin{gathered}
R_{2 p} \text { can therefore be described by equation [2], } \\
\qquad R_{2 p}=P q \frac{1}{T_{2 m}+\tau_{\mathrm{m}}}
\end{gathered}
$$

where $\tau_{m}$ is the inverse of the exchange rate constant $\mathrm{k}_{\mathrm{ex}}, q$ is the number of water molecules bound to $\mathrm{Gd}(\mathrm{III})$ and $P$ is the mole fraction of the chelate. At $319.9 \mathrm{~K}$ we are in the regime of very fast exchange and

$$
\begin{array}{r}
\tau_{m} \ll T_{2 m} . \\
R_{2 p} \cong P q \frac{1}{T_{2 m}}
\end{array}
$$

The transverse relaxation of ${ }^{17} \mathrm{O}$ bound directly to $\mathrm{Gd}(\mathrm{III})$ is governed by scalar relaxation and can be expressed at high magnetic field by equation $[4],{ }^{[i i i]}$

$$
\frac{1}{T_{2 M}}=\frac{S(S+1)}{3}\left(\frac{A}{\hbar}\right)^{2} \tau_{S 1}
$$

with $\tau_{s l}=\left(k_{e x}+1 / T_{l e}\right)^{-1}$. From variable temperature data we see that at $319.9 \mathrm{~K} k_{e x}>>1 / T_{l e}$. The pressure variation of $R_{2 p}$ is therefore linked to the pressure variation of the exchange rate constant $k_{e x}$ by equation [5] if we assume that the scalar coupling constant, $\mathrm{A} / \hbar$, is independent of pressure. ${ }^{[\mathrm{iv}]}$ 


$$
R_{2 p}=C \frac{1}{k_{e x}}
$$

The activation volume, $\Delta \mathrm{V}^{\ddagger}$, for the exchange of a water molecule can be obtained from equation [6] leading to the final expression for the pressure variation of $R_{2 p}$ (equation [7]).

$$
\begin{gathered}
k_{e x}=\frac{1}{\tau_{M}}=\left(\mathrm{k}_{\mathrm{ex}}\right)_{0}^{T} \exp \left\{-\frac{\Delta \mathrm{V}^{*}}{\mathrm{RT}} \mathrm{P}\right\} \\
\ln \left(R_{2 p}\right)=\text { const }+\frac{\Delta \mathrm{V}^{*}}{\mathrm{RT}} \mathrm{P}
\end{gathered}
$$

A linear fit leads to the activation volume $\Delta \mathrm{V}^{\ddagger}=-(5 \pm 1) \mathrm{cm}^{3} \mathrm{~mol}^{-1}$.

Table S2. Pressure dependence of ${ }^{17} \mathrm{O}$ transverse relaxation rates of [Gd(TREN-bisHOPO-TAMTRI) $\left.\left(\mathrm{H}_{2} \mathrm{O}\right)_{2}\right]^{-}, 1 / \mathrm{T}_{2 \mathrm{obs}}$, and of [Y(TREN-bisHOPO-TAM-TRI $\left.\left(\mathrm{H}_{2} \mathrm{O}\right)_{2}\right]^{-}, 1 / \mathrm{T}_{2 \text { ref, }}$ at $319.9 \mathrm{~K}$ and $9.4 \mathrm{~T}$ and $\mathrm{pH}$ 8.2 .

\begin{tabular}{|c|c|c|c|c|}
\hline $\mathbf{P} / \mathbf{M P a}$ & $1 / \mathrm{T}_{2 \mathrm{obs}} / \mathrm{s}^{-1}$ & $1 / \mathrm{T}_{2 \mathrm{ref}} / \mathrm{s}^{-1}$ & $\mathrm{R}_{2 \mathrm{p}} / \mathrm{s}^{-1}$ & $\operatorname{In}\left(\mathbf{R}_{\mathbf{2 p}}\right)$ \\
\hline 8.8 & 133 & 102 & 30.71 & 3.42 \\
\hline 45.5 & 124 & 99 & 25.31 & 3.23 \\
\hline 107.9 & 118 & 93 & 25.01 & 3.22 \\
\hline 158.4 & 111 & 88 & 22.63 & 3.12 \\
\hline 197.0 & 109 & 85 & 24.23 & 3.19 \\
\hline 181.6 & 109 & 86 & 22.69 & 3.12 \\
\hline 137.8 & 112 & 90 & 21.74 & 3.08 \\
\hline 90.5 & 120 & 95 & 25.59 & 3.24 \\
\hline 62.0 & 125 & 97 & 27.35 & 3.31 \\
\hline 27.1 & 130 & 101 & 29.80 & 3.39 \\
\hline 0.2 & 136 & 103 & 33.02 & 3.50 \\
\hline
\end{tabular}

(i) A. Cusanelli, L. Nicula-Dadci, U. Frey, A. E. Merbach, Inorg. Chem. 1997, 36, 2211.

(ii) S. Meiboom, D. Gill, Rev. Sci. Instrum. 1958, 29, 688.

(iii) Tóth, É.; Helm, L.; Merbach, A. E. In The Chemistry of Contrast Agents in Medical Magnetic Resonance Imaging; 1st ed.; Merbach, A. E., Tóth, É. Eds.; John Wiley \& Sons: Chichester, 2001, pp 45-119.

(iv) C. Cossy, L. Helm, A. E. Merbach, Inorg. Chem. 1989, 28, 2699. 